\title{
SOCIAL DEPRIVATION AND TOOTH DECAY IN NORTH WEST ENGLAND SCHOOLCHILDREN
}

\author{
Colwyn Jones, Senior Registrar in Dental Public Health \\ North West Dental Public Health Resource Centre \\ Keith Woods, Consultant in Dental Public Health \\ North West Lancashire \& Morecambe Bay Health Authorities \\ Chris Winard, Research Officer \\ North West Dental Public Health Resource Centre
}

\begin{abstract}
Objective To quantify the association between dental decay in Northwest schoolchildren and social deprivation as measured by the Jarman UPA index from the 1991 census.
\end{abstract}

Design An ecological study using data from the National Health Service Dental Epidemiology Programme and The Public Health Common Data set.

Setting District Health Authorities in the North West of England from 1992 to 1995.

Subjects Random samples of 5-, 12- and 14-year-old schoolchildren in South Cumbria and the District Health Authorities across the former Mersey and North Western Regions.

Results Positive significant correlations were demonstrated in all age groups; 12-year-olds $(r=0.53, p<0.01)$ in $1992 / 3$, 5 -year-olds $(r=0.69, \mathrm{p}<0.01)$ in 1993/4 and 14-year-olds $(r=$ $0.67, \mathrm{p}<0.01$ ) in $1994 / 5$. Dental decay in all age groups was positively and significantly associated with deprivation as measured by the Jarman UPA index.

Conclusion Mean levels of tooth decay in children was confirmed as a disease associated with socio-economic deprivation in the North West of England. The available evidence shows that despite increasing polarisation of decay to socially deprived groups of the population, the 'whole population' approach of water fluoridation would prevent tooth decay most effectively. Nevertheless, less effective evidence-based interventions (fluoride supplements) may have to be used to improve dental health in areas of socio-economic deprivation to narrow the 'Dental Health Divide'.

\section{INTRODUCTION}

Tooth decay in children, as with mortality and many diseases, has a social class gradient ${ }^{(1.2)}$. The 1983 national child dental survey showed that 5-year-old children from social classes IV and $\mathrm{V}$ had twice as many primary teeth with decay experience than those in classes I, II and III non-manual( ${ }^{(3)}$. Similarly, the 1993 national child dental survey findings for 15 -year-olds showed statistically significant associations between social class and $\mathrm{DMFT}^{(4)}$ (this term is explained below). Recently, the use of an index of material deprivation to identify young children at risk of dental caries has been reported $^{(5)}$.
A diversity of deprivation indices derived from small area statistics has been used to demonstrate the link between deprivation and health ${ }^{(6)}$. Jarman UPA (underprivileged area) scores are widely available and could potentially be used for targeting dental services if strongly associated with dental need. In this study the aim was to confirm if the association between dental caries and social deprivation exists, as measured by the Jarman UPA index at a District Health Authority level, and to quantify any association.

\section{METHOD}

This is an ecological study where the data were averaged over District Health Authorities in the North West Region (former North Western \& Mersey Regions including South Cumbria). The Jarman UPA index is used as an indicator of social deprivation. Its relationship to dental decay, as measured by the dmft/DMFT index, was explored. The $\mathrm{dmft} / \mathrm{DMFT}$ index is a composite measure of the number of decayed teeth, missing teeth due to decay and filled teeth. The standard convention uses lower case dmft for deciduous (baby or milk) teeth and upper case for permanent (adult or second) teeth. Individual dmft/DMFT scores can be combined to give a mean score for a population (or a representative sample of a population) from a geographical area. The National Health Service Dental Epidemiology Programme survey results at a District Health Authority level, as recorded between 1992 and 1995, were used ${ }^{(7,89)}$.

The Jarman UPA index is used to weight capitation payments to general medical practitioners and is readily available from the Public Health common data set. It is based on a weighted average of the following 1991 census variables $^{(10)}$ :

$\%$ of elderly living alone

$\%$ of residents in lone-parent families

\% of head of household in unskilled socio-economic group

$\%$ of the unemployed as a percentage of the economically active

\% of overcrowded households

$\%$ of change of address within one year

\% of households headed by person from the New Commonwealth or Pakistan.

Jarman UPA score have been used to rank all of the 
English districts in order of deprivation; an area with a larger score is more deprived than one with a lower score. A score of zero is the English average.

Pearson's correlation coefficients were calculated to test for the association between the two variables, Jarman UPA score and dmft/DMFT. The best fit regression lines were calculated on the statistical programme Surveyplus ${ }^{\circledR}$. Statistical significance was taken as $\mathrm{P}<0.05$.

\section{RESULTS}

The 1993/94 survey of 37,894 five-year-old children in the North West Region was a 1:2.3 sample. There was a positive, significant correlation between District Jarman UPA score and mean District dmft (Pearson's $r=0.69, \mathrm{P}<0.01, \mathrm{n}=30$ ). The best fit regression line equation was $\mathrm{Y}=0.02 \mathrm{X}+2.46$ (Figure 1).

In the 1992/93 survey of 12-year-olds, 23,190 children were seen which represents a 1:3.38 sample. Again, there was a positive, significant correlation between District Jarman UPA score and mean District DMFT (Pearson's $r=0.53$, $\mathrm{P}<0.01, \mathrm{n}=30$ ). The best fit regression line equation was $\mathrm{Y}=$ $0.012 \mathrm{X}+1.64$ (Figure 2).

The 1994/95 survey of 14-year-olds was a 1:5.6 sample consisting of 13,803 children. Again, the correlation was positive and significant between District Jarman UPA score and mean District DMFT (Pearson's $\mathrm{r}=0.57, \mathrm{P} 0.01, \mathrm{n}=30$ ). The best fit regression line equation was $\mathrm{Y}=0.02 \mathrm{X}+2.44$ (Figure 3).

\section{DISCUSSION}

The results confirm that dental decay in the three age groups, as with many diseases, has a strong, positive association with deprivation, as measured by the Jarman UPA index in the North West Region. It should be noted that this association is not indicative of the causes of dental decay.
The strength of the association became weaker as the age of the study samples increased and a number of factors may contribute to this trend. Case ascertainment (and hence sample representativeness) may be a problem in older children. The sampling method for the surveys uses state schools and an increasing number of older children travel outside their own area for schooling, some of which will be in non-state schools. Truancy rates are also higher among older children. The older children will have also become more independent in eating habits (frequency and amount of sugar intake) and grooming behaviour (frequency of fluoride toothpaste use being the main influence), which may be atypical of their social class.

Dental decay is reported to be becoming increasingly polarised to socially deprived groups of the population ${ }^{(11)}$ who are least likely to attend for restorative and preventive treatment. An enormous effort would be needed to bring all of these children into care and it has been shown that the most cost-effective way to improve dental health overall is through a 'whole population' strategy, rather than attempting to target them via a high risk approach. The available evidence clearly shows that the most effective primary preventive measure capable of reducing the 'dental health divide' is fluoridation of the domestic water supply ${ }^{(12)}$. If this is not available in the near future then less effective, alternative strategies, such as systemic fluoride supplements, would need to be targeted at the most socially deprived areas within each Health Authority boundary.

In conclusion, dental caries is confirmed as a disease associated with social deprivation in 5-, 12- and 14-year-old schoolchildren in the north west of England. Jarman UPA scores correlate well with mean levels of tooth decay and could be useful in planning dental services for children in relation to need.

\section{Acknowledgments}

We wish to thank the dentists and their assistants who carried out the surveys in the North West Region.

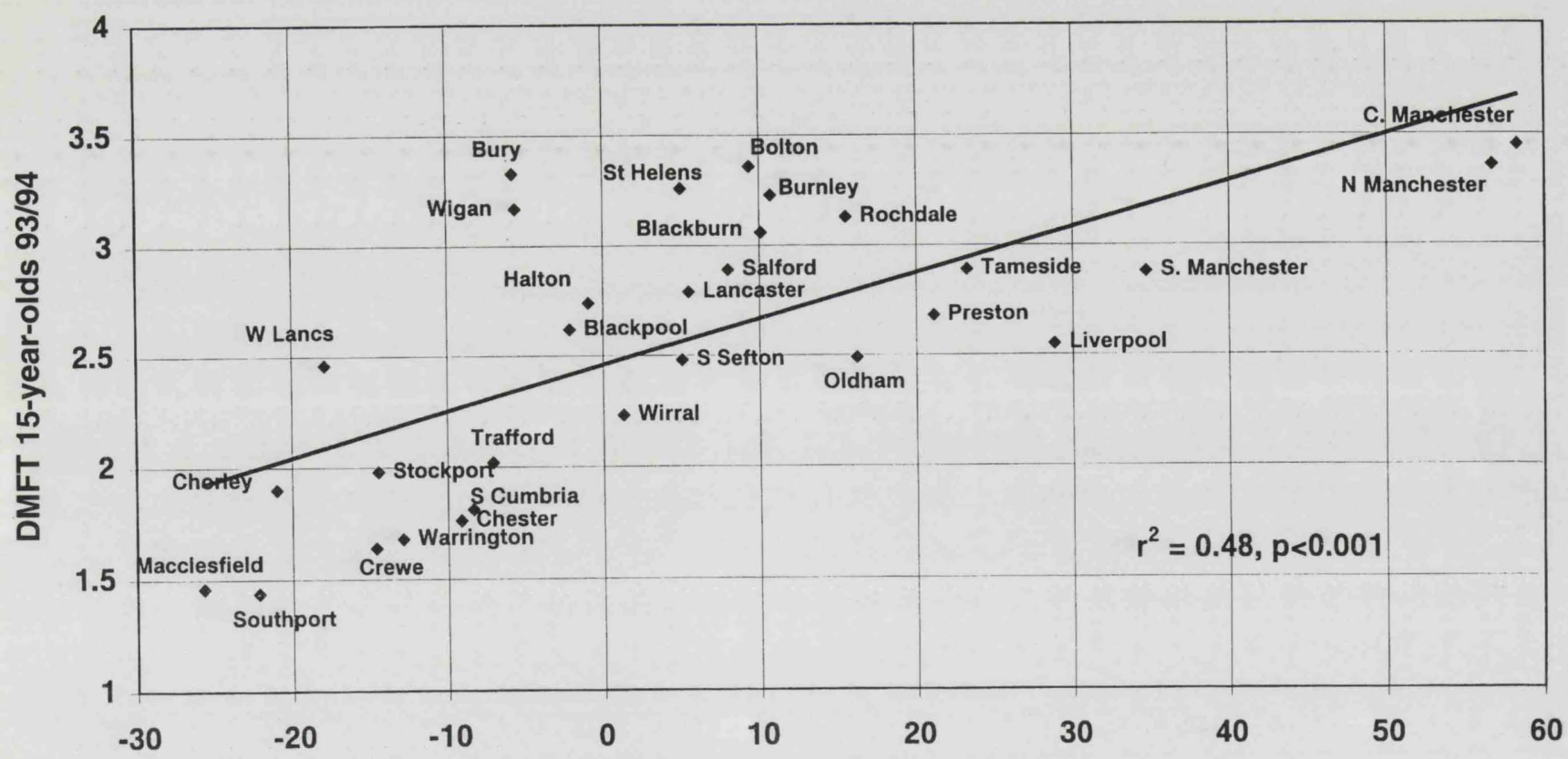

District Jarman UPA score 1991 


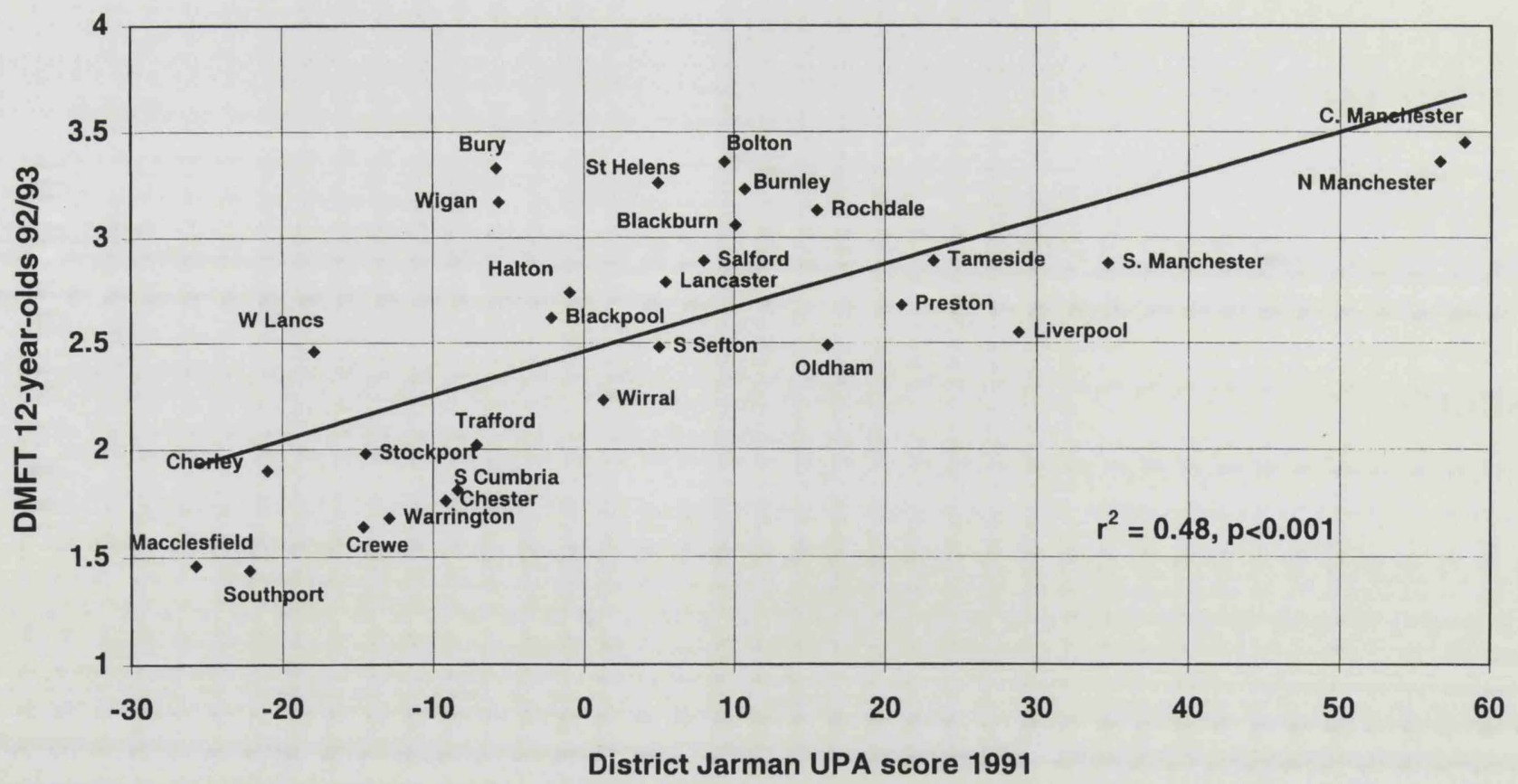

Fig 2 North West Region, 12-year-olds mean dmft 1992/93 \& District Jarman score, with best fit regression line.

\section{REFERENCES}

1 The Black Report. Report of a Research Working Group. Inequalities in Health. London. HMSO. 1980

2 Beal JF Social factors and preventive dentistry. In Murray JJ(Ed). The prevention of dental disease. Chapter 11. Oxford University Press 1990

3 Todd JE, Dodd T Children's dental health in the United Kingdom 1983. London. HMSO. 1985

4 O'Brien M Children's dental health in the United Kingdom 1993. London. HMSO. 1994

5 Provart SJ, Carmicheal CL The use of an index of material deprivation to identify groups of children at risk of dental caries in County Durham. Community Dental Health $1995 ; 12: 138-142$

6 Carstairs V Deprivation indices: their interpretation and use in relation to health. J Epidemiol Comm Health 1995; 49(Suppl 2):S3-S8

7 Pitts NB, Palmer JD The dental caries experience of 5-, 12- and 14-year-old children in Great Britain. Surveys coordinated by the British Association for the Study of Community Dentistry in 1991/92, 1992/93 and 1990/91. Community Dental Health 1994; 11:42-52

8 Pitts NB, Palmer JD The dental caries experience of 5year-old children in Great Britain. Surveys coordinated by the British Association for the Study of Community Dentistry in 1993/94. Community Dental Health 1995; 12:52-58

9 Pitts NB, Evans DJ, Palmer JD The dental caries experience of 14-year-old children in Great Britain. Surveys coordinated by the British Association for the Study of Community Dentistry in 1994/95. Community Dental Health 1996; 13:51-58

10 Jarman B Identification of underprivileged areas. BMJ 1983; 286:1705-1709

11 Pitts NB Discovering Dental Public Health: from Fisher to the future. Community Dental Health 1994; 11:172-178

12 Downer MC The 1993 national survey of children's dental health: a commentary on the preliminary report. BDJ 1995; 176:209-214

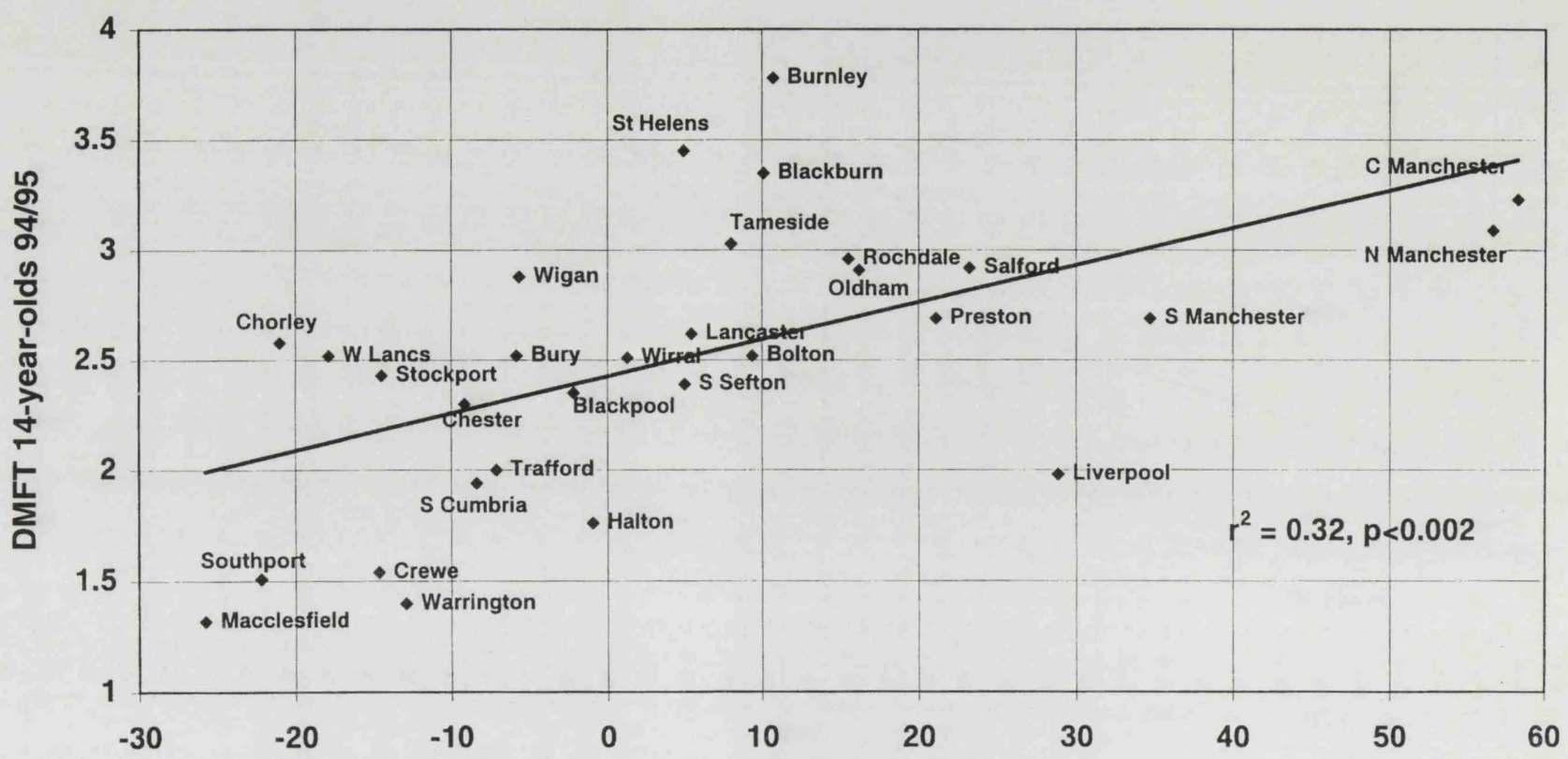

District Jarman UPA score 1991 